\title{
Embedded Switched-Inductor Z-Source Inverters
}

\author{
Minh-Khai Nguyen ${ }^{\dagger}$, Young-Cheol Lim*, Young-Hak Chang ${ }^{* *}$, and Chae-Joo Moon ${ }^{* * *}$ \\ 'Dept. of Electrical and Electronics Eng., Nguyen Tat Thanh University, Ho Chi Minh City, Viet Nam \\ ${ }^{*}$ Dept. of Electrical Eng., Chonnam National University, Gwangju, Korea \\ ** Dept. of Control and Robot Eng., Mokpo National University, Mokpo, Korea \\ ${ }^{* * *}$ Dept. of Electrical Eng., Mokpo National University, Mokpo, Korea
}

\begin{abstract}
In this paper, a ripple input current embedded switched-inductor Z-source inverter (rESL-ZSI) and a continuous input current embedded switched-inductor Z-source inverter (cESL-ZSI) are proposed by inserting two dc sources into the switched-inductor cells. The proposed inverters provide a high boost voltage inversion ability, a lower voltage stress across the active switching devices, a continuous input current and a reduced voltage stress on the capacitors. In addition, they can suppress the startup inrush current, which otherwise might destroy the devices. This paper presents the operating principles, analysis, and simulation results, and compares them to the conventional switched-inductor Z-source inverter. In order to verify the performance of the proposed converters, a laboratory prototype was constructed with $60 \mathrm{~V}_{\mathrm{dc}}$ input to test both configurations.
\end{abstract}

Key words: Z-source inverter, embedded Z-source inverter, switched-inductor, boost inversion ability, continuous current

\section{INTRODUCTION}

High-performance voltage-source inverters [1] are widely used in various applications such as uninterruptible power supplies, distributed power systems, ac motor drives, and hybrid electric vehicles. However, the traditional voltage-source inverter has a couple of major problems: 1) it cannot have an ac output voltage higher than the dc source voltage and can only provide buck dc-ac power conversion; 2) shoot through, generated by both power switches in a leg, is forbidden. For applications where a low input voltage is inverted to a high ac output voltage, an additional dc-dc boost converter is needed to obtain a desired ac output. The additional power converter performs two-stage power conversion with high cost and low efficiency. Unlike traditional voltage-source inverters [1], Z-source inverters were proposed in [2] in order to accomplish single-stage power conversion with buck-boost abilities. In the Z-source inverter, both of the power switches in a leg can be turned on at the same time and thereby eliminate the dead time. This

Manuscript received Nov. 15, 2011; revised Nov. 1, 2012

Recommended for publication by Associate Editor Honnyong Cha.

†Corresponding Author: nmkhai@ntt.edu.vn

Tel: +84-8-39408684, Fax: +84-8-39404759, Nguyen Tat Thanh Univ.

${ }^{*}$ Dept. of Electrical Eng., Chonnam National University, Korea.

*** Dept. of Control and Robot Eng., Mokpo National University, Korea.

*** Dept. of Electrical Eng., Mokpo National University, Korea. significantly improves the reliability and reduces the output waveform distortion. Various Z-source inverter topologies have been reported in many different studies. Work on Z-source inverters has focused on pulse-width modulation (PWM) strategies [3], [4], applications [5], [6], modeling and control [7], [8], direct ac-ac converters [9], [10], and other Z-network topologies [11]-[13]. A class of quasi-Z-source inverters was proposed in [11], [12] that were designed to overcome the shortcomings of the classic Z-source inverter. Quasi-Z-source inverters have some advantages, such as a reduction in the passive component ratings and an improvement in the input profiles.

Some papers have recently focused on improving the boost factor of the $\mathrm{Z}$-source inverter by using a very high modulation index in order to achieve an improvement in the output waveform [14]-[17]. For instance, studies in [14]-[16] add inductors, capacitors, and diodes to the Z-impendence network in order to produce a high dc link voltage for the main power circuit from a very low input dc voltage. In [17], two inductors in the impedance Z-network are replaced by a transformer with a turn ratio of $2: 1$ in order to obtain a high voltage gain. These topologies suit solar cell and fuel cell applications, since they require a high voltage gain in order to match the source voltage to the line voltage. Applying switched-capacitor, switched-inductor, hybrid switched-capacitor/switched-inductor structures, voltage-lift techniques, and voltage multiplier cells [18] to the dc-dc 
conversion process provides a high boost in cascade and transformerless structures with a high efficiency and high power density. A successful combination of the Z-source inverter and switched-inductor structure, called the switched-inductor Z-source inverter (SL-ZSI) [14], provides a strong step-up inversion that overcomes the boost limitations of the classic Z-source inverter (ZSI) [2].

The embedded Z-source inverter developed in [19] is built by inserting dc sources into the $\mathrm{X}$-shaped impedance network. Because the dc sources connect directly to the impedance network inductors, the dc input current in the embedded $Z$-source inverter flows smoothly, compared to that found in a traditional Z-source inverter [2]. The embedded Z-source inverter assumes two sources can produce the same voltage gain as found in a traditional $Z$-source inverter. The embedded Z-source inverter provides a continuous input current without adding an input passive filter and also a lower voltage on the capacitors.

This paper applies the switched-inductor structure to the embedded-Z-source topology in order to create two new types of inverters, a ripple input current embedded switched-inductor Z-source inverter (rESL-ZSI) and a continuous input current embedded switched-inductor Z-source inverter (cESL-ZSI). The proposed inverters have a high boost voltage inversion ability and a continuous input current. Compared to the SL-ZSI, the proposed rESL-ZSI and cESL-ZSI reduce the voltage stress on the capacitors and improve the reliability. In addition, the proposed inverters avoid the startup inrush current that could destroy the devices. The operating principles, analysis, and simulation results are compared to the switched-inductor Z-source inverter. A laboratory prototype based on a TMS320F2812 digital signal processor (DSP) verifies both of the converter configurations. We also performed a participative simulation integral manufacturing (PSIM) simulation.

\section{TRADITIONAL Z-SOURCE INVERTER TOPOLOGIES}

Fig. 1(a) shows the original ZSI topology [2] in which the two-port impedance network couples the main inverter circuit to the dc voltage source. It consists of two inductors $\left(L_{l}\right.$ and $L_{2}$ ) and two capacitors $\left(C_{1}\right.$ and $\left.C_{2}\right)$ connected in an $\mathrm{X}$ configuration. An additional shoot-through zero state is added to the switching states in order to boost the voltage. When the input voltage is large enough to produce the desired ac voltage, the shoot-through zero state is not used and the Z-source inverter operates as a buck inverter-just like a conventional voltage-source inverter. In the original ZSI, the current drawn from the source is discontinuous. This is a limitation in some applications, and a decoupling capacitor bank at the front end is sometimes used to avoid the current discontinuity and protect the energy source.

The embedded Z-source inverter developed in [19] is

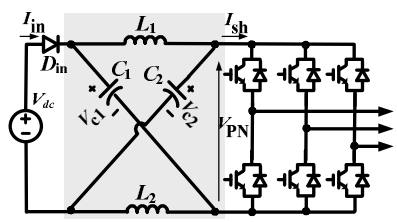

(a)

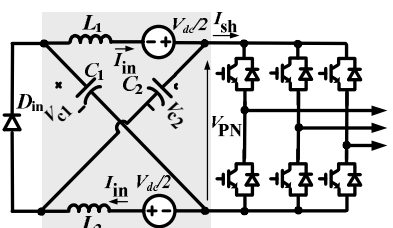

(b)
Fig. 1. (a) Original Z-source inverter and (b) embedded Z-source inverter with a continuous input current.

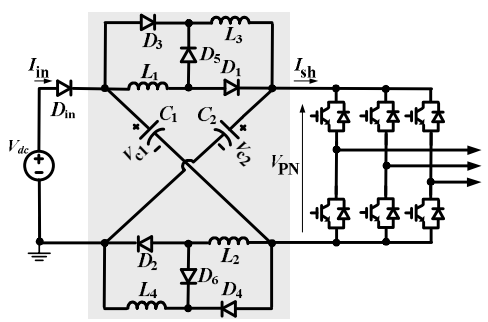

Fig. 2. Switched-inductor Z-source inverter (SL-ZSI) with a discontinuous input current.

designed to insert dc sources into the $\mathrm{X}$-shaped impedance network. Fig. 1(b) shows a continuous input current embedded Z-source inverter with two isolated dc sources. Because the dc sources are directly connected to the impedance network inductors, the dc input current in the embedded Z-source inverter flows smoothly compared to the classic Z-source inverter [2]. The embedded Z-source inverter assumes that the two sources can produce the same voltage gain as the traditional $\mathrm{Z}$-source inverter. The ratio between the dc-link voltage across the inverter bridge $V_{P N}$ and the input dc voltage $V_{d c}$, called the boost factor in the classical ZSI and embedded ZSI, is expressed by:

$$
B_{z}=\frac{V_{P N}}{V_{d c}}=\frac{1}{1-2 T_{0} / T}=\frac{1}{1-2 D} .
$$

where $T_{0}$ is the interval of the shoot-through state during switching period $T$ and $D=T_{0} / T$ is the duty cycle of each cycle.

In order to improve the main circuit output power quality, the switched-inductor Z-source inverter (SL-ZSI) [14] possesses high voltage-conversion ratios with a very short shoot-through state. Fig. 2 shows the SL-ZSI topology. It consists of four inductors $\left(L_{1}, L_{2}, L_{3}\right.$ and $\left.L_{4}\right)$, two capacitors $\left(C_{1}\right.$ and $\left.C_{2}\right)$, and seven diodes $\left(D_{i n}, D_{1}, D_{2}, D_{3}, D_{4}, D_{5}\right.$ and $\left.D_{6}\right)$ The combinations of $L_{1}-L_{3}-D_{1}-D_{3}-D_{5}$ and $L_{2}-L_{4}-D_{2}-D_{4}-D_{6}$ act as the switched-inductor cells. The boost factor of this inverter [14] is increased to:

$$
B_{s}=\frac{1+T_{0} / T}{1-3 T_{0} / T}=\frac{1+D}{1-3 D} .
$$

Despite this increase in boost inversion, the SL-ZSI has a significant drawback in that the current drawn from the source is discontinuous. This is a limitation in some applications, and a decoupling capacitor bank at the front end is sometimes used to avoid the current discontinuity and protect the energy source. In addition, the SL-ZSI cannot suppress the startup inrush current; the resulting voltage and 
current spike can destroy the device.

\section{EMBEDDED SWITCHED-INDUCTOR Z-SOURCE INVERTERS}

Fig. 3 shows the two proposed embedded switched-inductor Z-source inverters, each having two isolated dc sources in which the components used are the same as those shown in Fig.2. The difference between the proposed topologies and the SL-ZSI topology is in the positions of the dc sources. In Fig. 3(a), each isolated dc source is directly connected to the switched-inductor cell $\left(L_{1}-L_{3}-D_{1}-D_{3}-D_{5}\right.$ or $\left.L_{2}-L_{4}-D_{2}-D_{4}-D_{6}\right)$. Therefore, a ripple appears on the input current of this topology, denoted as a ripple input current embedded switched-inductor Z-source inverter (rESL-ZSI). Conversely, the dc sources in Fig. 3(b) are placed in series with inductors $\left(L_{2}\right.$ and $\left.L_{3}\right)$ which results in a continuous input current. The topology shown in Fig. 3(b) is called a continuous input current embedded switched-inductor Z-source inverter (cESL-ZSI). Because the sources in the ESL-ZSI are connected to either an inductor or a switched-inductor cell, the proposed inverters have a flatter input current in comparison to the classic SL-ZSI [14]. The advantages of the proposed inverters are described as follows: 1) the input current is continuous; 2) it provides inrush current suppression at startup, unlike the traditional SL-ZSI in Fig. 2, because no current flows to the main circuit at startup; 3) the capacitor stress voltage is reduced; 4) high boost factor can be obtained by using a small shoot-through duty cycle; and 5) two separate dc sources can be applied.

Like the original Z-source inverter, the proposed inverters have extra shoot-through zero states in addition to the traditional six active and two zero states. Therefore, the operating principles of the proposed inverters are similar to those of the original Z-source inverters and the switched-inductor Z-source inverter. For the purpose of analysis, the operating states are simplified into shoot-through and non-shoot-through states. Figs. 4 and 5 show the rESL-ZSI and the cESL-ZSI equivalent circuits, respectively. In the non-shoot-through states, as shown in Figs. 4(a) and 5(a), the proposed inverter has six active states and two zero states in the inverter main circuit. During the non-shoot-through state, $D_{i n}, D_{5}$ and $D_{6}$ are on, whereas $D_{l}$, $D_{2}, D_{3}$ and $D_{4}$ are off. $L_{1}$ and $L_{3}$ are connected in series; $L_{2}$ and $L_{4}$ are connected in series. Capacitors $C_{1}$ and $C_{2}$ are charged, whereas the inductors $L_{1}, L_{2}, L_{3}$, and $L_{4}$ transfer energy from the dc voltage sources to the main circuit. The corresponding voltages across $L_{1}, L_{2}, L_{3}$ and $L_{4}$ in this state are $V_{L 1 \_n o n}, V_{L 2 \_n o n}, V_{L 3 \_n o n}$ and $V_{L 4 \_n o n}$, respectively.

In the shoot-through states, as shown in Figs. 4(b) and 5(b), the inverter side is shorted by both the upper and lower switching devices in the phase legs. During the shoot-through state, $D_{i n}, D_{5}$ and $D_{6}$ are off, whereas $D_{1}, D_{2}, D_{3}$ and $D_{4}$ are on. $L_{l}$ and $L_{3}$ are connected in parallel; $L_{2}$ and $L_{4}$ are connected in

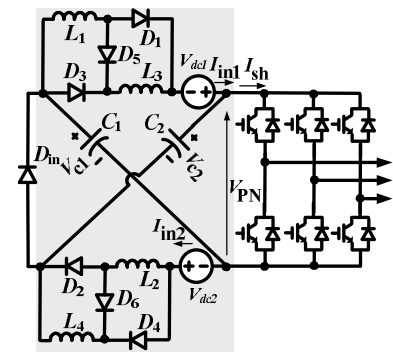

(a)

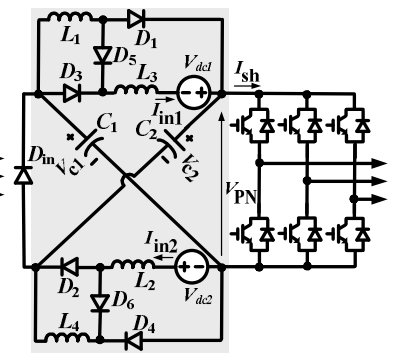

(b)
Fig. 3. Embedded switched-inductor Z-source inverters: (a) ripple input current topology (rESL-ZSI) and (b) continuous input current (cESL-ZSI) topology.

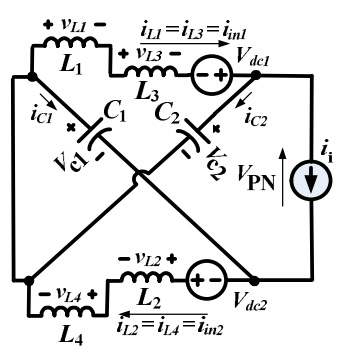

(a)

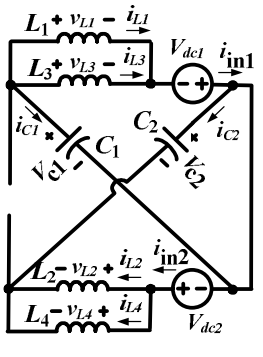

(b)
Fig. 4. Operating states of the rESL-ZSI: (a) non-shoot-through and (b) shoot-through.

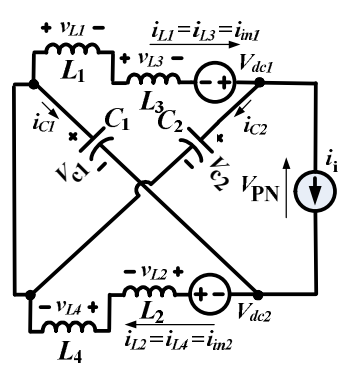

(a)

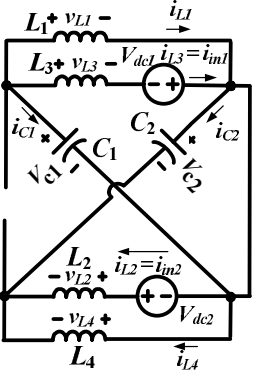

(b)
Fig. 5. Operating states of the cESL-ZSI: (a) non-shoot-through and (b) shoot-through.

parallel. Capacitors $C_{1}$ and $C_{2}$ are discharged, whereas inductors $L_{1}, L_{2}, L_{3}$ and $L_{4}$ store energy.

\section{A. rESL-ZSI Circuit Analysis}

In the non-shoot-through state, as shown in Fig. 4(a), we get:

$$
\begin{gathered}
v_{L 1}+v_{L 3}=V_{d c 1}-V_{C 2} \\
v_{L 2}+v_{L 4}=V_{d c 2}-V_{C 1} \\
V_{P N}=V_{C 1}+V_{C 2} \\
i_{C l}=I_{L 2}-i_{i} \quad i_{C 2}=I_{L 1}-i_{i} \quad i_{\text {inl }}=I_{L 1} \quad i_{\text {in } 2}=I_{L 2} .
\end{gathered}
$$

In the shoot-through state, as shown in Fig. 4(b), we obtain:

$$
\begin{gathered}
v_{L 1}=v_{L 3}=V_{C 1}+V_{d c 1} \\
v_{L 2}=v_{L 4}=V_{C 2}+V_{d c 2} \\
i_{C 1}=-2 I_{L 1} \quad i_{C 2}=-2 I_{L 2} \\
i_{i n 1}=2 I_{L 1} \quad i_{i n 2}=2 I_{L 1} .
\end{gathered}
$$

Applying the volt-second balance principle to the inductors and capacitors, from (6)-(9) we obtain: 


$$
\left\{\begin{array}{l}
V_{L 1 \_n o n}=V_{L 3 \_n o n}=\frac{-D}{1-D}\left(V_{d c 1}+V_{C 1}\right) \\
V_{L 2 \_n o n}=V_{L 4 \_n o n}=\frac{-D}{1-D}\left(V_{d c 2}+V_{C 2}\right) \\
I_{L}=I_{L 1}=I_{L 2}=I_{L 3}=I_{L 4}=\frac{1-D}{1-3 D} i_{i} \\
I_{i n}=I_{i n 1}=I_{\text {in } 2}=(1+D) I_{L} .
\end{array}\right.
$$

Substituting (10) to (3) and (4), we get:

$$
\left\{\begin{array}{l}
(1+D) V_{d c 1}+2 D V_{C 1}-(1-D) V_{C 2}=0 \\
(1+D) V_{d c 2}-(1-D) V_{C 1}+2 D V_{C 2}=0 .
\end{array}\right.
$$

Solving (11), we obtain:

$$
\left\{\begin{array}{l}
V_{C 1}=\frac{2 D V_{d c 1}+(1-D) V_{d c 2}}{1-3 D} \\
V_{C 2}=\frac{(1-D) V_{d c 1}+2 D V_{d c 2}}{1-3 D} .
\end{array}\right.
$$

The peak dc-link voltage across the inverter main circuit is expressed in (5) and can be rewritten as:

$$
V_{P N}=V_{C 1}+V_{C 2}=\frac{1+D}{1-3 D}\left(V_{d c 1}+V_{d c 2}\right)=B_{r} V_{d c},
$$

where $V_{d c}=V_{d c 1}+V_{d c 2}$ is the total input voltage. The boost factor of the proposed rESL-ZSI, $B_{r}$, is defined by:

$$
B_{r}=\frac{1+D}{1-3 D} \text {. }
$$

Comparing (14) to (2), the boost factor of the proposed rESL-ZSI is the same as that found in the SL-ZSI [14].

\section{B. cESL-ZSI Circuit Analysis}

In the non-shoot-through state, as shown in Fig. 5(a), the obtained equations are similar to (3)-(6). In the shoot-through state, as shown in Fig. 5(b), we obtain:

$$
\begin{aligned}
& v_{L I}=V_{C l} \\
& v_{L 2}=V_{C 2}+V_{d c 2} \\
& v_{L 4}=V_{C 2} \\
& v_{L 3}=V_{C l}+V_{d c I} \\
& i_{C 1}=-2 I_{L 3} \quad i_{C 2}=-2 I_{L 2}
\end{aligned}
$$

Applying the volt-second balance principle to inductors and capacitors, from (3), (4), (6), and (15)-(17), obtains:

$$
\left\{\begin{array}{l}
V_{C 1}=\frac{2 D V_{d c 1}+(1-D) V_{d c 2}}{(1+D)(1-3 D)} \\
V_{C 2}=\frac{(1-D) V_{d c 1}+2 D V_{d c 2}}{(1+D)(1-3 D)} \\
I_{L}=I_{L 1}=I_{L 2}=I_{L 3}=I_{L 4}=\frac{1-D}{1-3 D} i_{i} \\
I_{i n}=I_{i n 1}=I_{i n 2}=I_{L} .
\end{array}\right.
$$

The peak dc-link voltage cross the inverter main circuit is expressed in (5) and can be rewritten as:

$$
V_{P N}=V_{C 1}+V_{C 2}=\frac{1}{1-3 D}\left(V_{d c 1}+V_{d c 2}\right)=B_{c} V_{d c} .
$$

The boost factor of the proposed cESL-ZSI, $B_{c}$, is defined by:

$$
B_{c}=\frac{1}{1-3 D} .
$$

Comparing (20) to (2), the boost factor of the proposed cESL-ZSI is lower than that found in the SL-ZSI [14].

Fig. 6 shows the boost factor versus the duty cycle for the different topologies; curves 1, 2, and 3 are derived from (1),

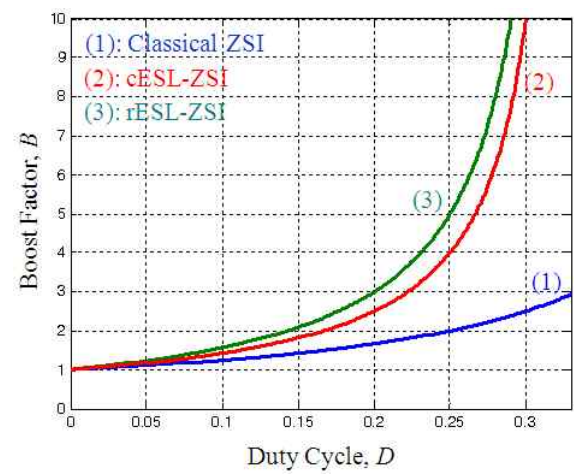

Fig. 6. Comparison of the boost ability of proposed topologies to classic topology: (1) classic Z-source inverter, ZSI, (2) proposed continuous input current embedded switched-inductor Z-source inverter, cESL-ZSI, and (3) proposed ripple input current embedded switched-inductor Z-source inverter, rESL-ZSI.

(20), and (14), respectively. The boost ability of the proposed embedded switched-inductor Z-source inverters is higher than that of the classic Z-source inverter [2]. From (12), (13), (18) and (19), we can observe that the proposed inverter topologies are symmetrical when $V_{d c l}=V_{d c 2}=V_{d c} / 2$. In case two split dc voltage sources $V_{d c} / 2$ are not identical, there is no problem at the operation of proposed topologies. In this case, the proposed inverter topologies are asymmetrical and, thereby, $V_{c l} \neq V_{c 2}$ as shown in (12) and (18).

\section{PWM Control for the Proposed Embedded} Switched-Inductor Z-Source Inverters

Three basic PWM control methods, simple, maximum [3], and constant boost control [4], work with the proposed ESL-ZSIs. These methods are presented in details in [3] and [4]. The simple boost control method was used for the analysis, simulation, and experiment in this paper. The simple boost control method uses a straight line, whose amplitude is equal to or greater than the peak value of the three-phase references, in order to generate the shoot-through states. The duty cycle of the shoot-through state, $D$ can be adjusted as a constant value. The maximum duty cycle of the shoot-through state is:

$$
D=(1-M)
$$

where $M$ is the modulation index

Substituting (21) into (14) and (20), we get the equivalent boost factor for the rESL-ZSI and cESL-ZSI:

$$
\left\{\begin{array}{l}
B_{r}=\frac{2-M}{3 M-2} \\
B_{c}=\frac{1}{3 M-2} .
\end{array}\right.
$$

The peak value of the phase voltage from the inverter output is expressed by:

$$
\hat{\mathcal{v}}_{p h}=M \cdot V_{P N} / 2=M \cdot B \cdot V_{d c} / 2,
$$

where $B$ is $B_{r}$ or $B_{c}$.

The voltage gains $(M B)$ of the rESL-ZSI and cESL-ZSI are defined by: 


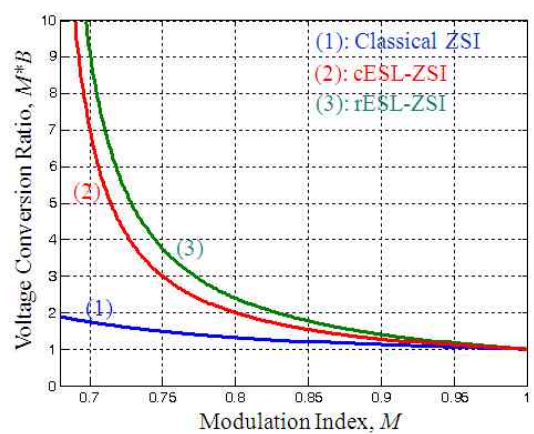

Fig. 7. Voltage conversion ratios versus modulation index for different topologies using simple boost control method.

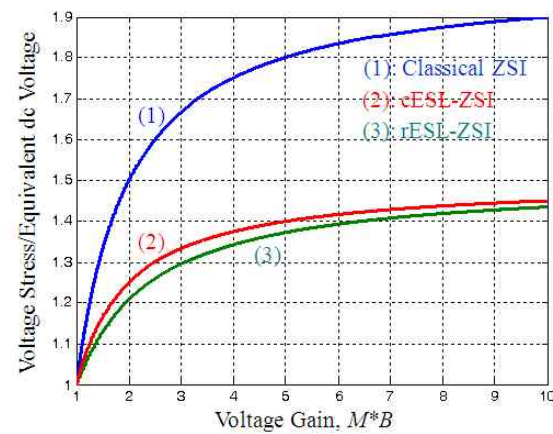

Fig. 8. Voltage stress comparison of the proposed embedded switched-inductor Z-source inverters to the classic ZSI.

$$
\left\{\begin{array}{l}
G_{r}=\frac{\hat{\mathcal{V}}_{p h}}{V_{d c} / 2}=M \cdot B_{r}=\frac{2 M-M^{2}}{3 M-2} \\
G_{c}=M \cdot B_{c}=\frac{M}{3 M-2} .
\end{array}\right.
$$

Fig. 7 shows the voltage conversion ratios versus the modulation indices of the different topologies under simple boost control. Compared with the classic Z-source inverter [2] and using the same modulation index, the proposed inverters provide a higher voltage boost inversion. Therefore, for the same voltage conversion ratio, the proposed inverters use a higher modulation index in order to improve the inverter output quality.

The voltage stress $V_{s}$ across the switching devices can be defined by the ratio of its peak dc link voltage to the minimum dc voltage $\left(G V_{d c}\right)$ needed for the traditional ZSI to generate the same ac output voltage at $M=1$ [4]. This ratio relates to the extra cost for the inverters to obtain the voltage boost and to the higher voltage stress. The respective ratios of the voltage stress to the equivalent $\mathrm{dc}$ voltage for the rESL-ZSI and cESL-ZSI can be expressed as:

$$
\left\{\begin{array}{l}
\frac{V_{S}}{G_{r} V_{d c}}=\frac{B_{r} V_{d c}}{G_{r} V_{d c}}=\frac{2+3 G-\sqrt{9 G^{2}-4 G+4}}{2 G-9 G^{2}+3 G \sqrt{9 G^{2}-4 G+4}} \\
\frac{V_{S}}{G_{c} V_{d c}}=\frac{B_{c} V_{d c}}{G_{c} V_{d c}}=\frac{3}{2}-\frac{1}{2 G} .
\end{array}\right.
$$

Fig. 8 shows the active switch voltage stress comparison of the proposed embedded switched-inductor Z-source inverters to the classic ZSI. As shown in Fig. 8, for the same dc-ac output voltage gain the proposed inverters have a lower

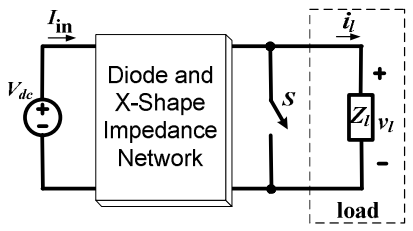

Fig. 9. Unified and simplified equivalent circuit of impedance-type power inverters, i.e., proposed inverters, switched-inductor ZSI, embedded ZSI, and classic ZSI.

voltage stress across the active switching devices. Therefore, the proposed inverters have many benefits in high voltage gain applications.

\section{Input Current Ripple and Stress Comparisons to the Other Topologies}

Differing control conditions cause varied input current ripples in power inverters. For comparison, we assume that the inductor current ripple for all of the inverters is small and ignorable. The simple boost control was used to analyze the characteristics of the input current ripple for the proposed rESL-ZSI, the proposed cESL-ZSI, the SL-ZSI [14], the embedded ZSI [19], and the classic ZSI [2]. This simplifies them, as shown in Fig. 9. The ac side circuit is represented by its simplified equivalent dc load [7]. An inductive load impedance $\left(Z_{l}=R_{l}+s L_{l}\right)$ directly connects in parallel with the active switch $S$ in Fig. 9, where $i_{l}$ and $v_{l}$ are the instantaneous load current and voltage, respectively. $I_{l}$ and $V_{l}$ are the average current and voltage during a switching cycle in the steady state.

Using the steady-state analysis method found in [7] for Fig. 9, we obtained the voltage and current stresses on the main components, such as the power switch, $D_{i n}, L, C$, and the dc link. For the switched-inductor Z-source inverter, the input current is expressed as:

$$
I_{\text {in }}=2 I_{L}-I_{l}
$$

In the shoot-through state, $I_{i n}=0$, and in the traditional zero-state, $I_{l}=0$; therefore, $I_{i n}=2 I_{L}$. In the active states, $I_{i n}=$ $2 I_{L}-I_{l}$. In the steady state, the inductor current of the switched-inductor Z-source inverter as shown in Fig. 2 is expressed by:

$$
I_{L}=\left.\frac{1-D}{1-3 D} I_{l}\right|_{D=1-M}=\frac{M}{3 M-2} I_{l} .
$$

Substituting (27) into (26), the average input current of the switched-inductor Z-source inverter [14] is:

$$
\overline{I_{\text {in }}}=\left.(1-D)\left(2 I_{L}-I_{l}\right)\right|_{\mathrm{D}=1-M}=(2-M) I_{L} \text {. }
$$

Fig. 10 shows the detailed input current for the SL-ZSI topology. The deviation of the input current and its average value is expressed by:

$$
\Delta I_{\text {in }}=\left|I_{\text {in }}-(2-M) I_{L}\right|=\left|2 I_{L}-I_{l}-(2-M) I_{L}\right|=\left|M \cdot I_{L}-I_{l}\right| \text {. }
$$

For the rESL-ZSI shown in Fig. 3(a), the input current in the non-shoot-through state is $I_{L}$; the input current in shoot-through state is $2 I_{L}$. The average input current of the rESL-ZSI, as expressed in (10), is: 


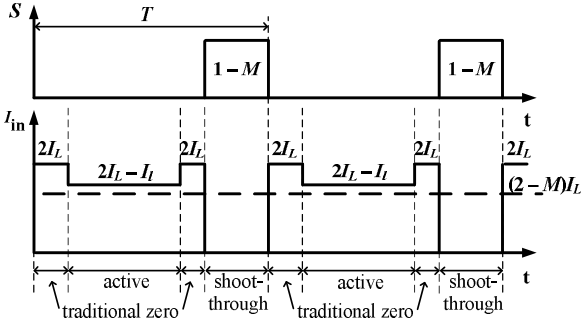

Fig. 10. SL-ZSI input current ripple.

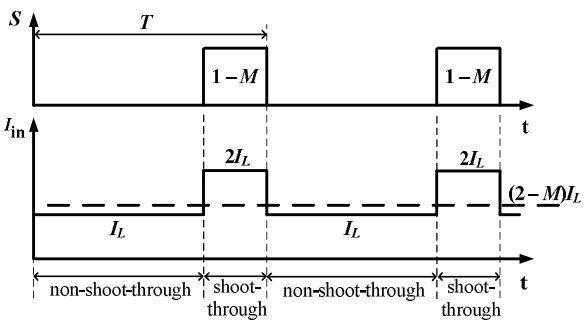

Fig. 11. rESL-ZSI input current ripple.

$$
\overline{I_{\text {in }}}=\left.(1+D) I_{L}\right|_{\mathrm{D}=1-M}=(2-M) I_{L} .
$$

The detailed input current for the proposed rESL-ZSI topology is shown in Fig. 11. The deviation of the input current and its average value is expressed by:

$$
\Delta I_{\text {in }}=\left|I_{\text {in }}-(2-M) I_{L}\right|=\left|I_{L}-(2-M) I_{L}\right|=\left|(1-M) I_{L}\right| \text {. }
$$

For the cESL-ZSI shown in Fig. 3(b), the input current is $I_{L}$. Therefore, the input current ripple in the cESL-ZSI is negligible and equal to zero. Table I compares the input current ripple equations for the proposed inverters to the other topologies for the same $M$ and $V_{d c}$. In Table I, the peak value of the phase voltage $\hat{v}_{p h}$ from the inverter output is obtained using the simple boost control method [3]. Table I shows that the voltage and current stresses of the proposed cESL-ZSI are lower than those of the rESL-ZSI and of the SL-ZSI for the same $M$ and $V_{d c}$.

When the cESL-ZSI or the rESL-ZSI replaces a SL-ZSI [14] in a particular case, $V_{d c}$ and $\hat{v}_{p h}$ are usually fixed. If we guarantee that the modulation index in the SL-ZSI [14] and the rESL-ZSI is $s$, the corresponding modulation index in the cESL-ZSI will be $\frac{2 s^{2}-4 s}{3 s^{2}-3 s-2}$ in order to produce the same $\hat{v}_{p h}$ from the same $V_{d c}$, when using the simple boost control. Table II gives the resulting voltage and current stresses of the proposed rESL-ZSI, the proposed cESL-ZSI and the SL-ZSI. The proposed inverters incur lower voltage stress on the capacitors, and a lower input current ripple in comparison with the SL-ZSI [14] for the same $V_{d c}, \hat{v}_{p h}$ and $R_{l}$.

The current stresses and voltage stress on the switches and diodes of the proposed rESL-ZSI are the same as those of the SL-ZSI, whereas the current stresses and voltage stress on the switches and diodes of the proposed cESL-ZSI are higher than those of the SL-ZSI for the same $V_{d c}, \hat{v}_{p h}, R_{l}$ and passive components.
TABLE I

Governing CURRENT AND VOLTAGE EQUATIONS For THE SAME

\begin{tabular}{|c|c|c|c|c|c|}
\hline & "rESL-ZSI & $\begin{array}{c}\text { cESL-Z } \\
\text { SI } \\
\end{array}$ & SL-ZSI & \begin{tabular}{|c|} 
Embedded \\
ZSI \\
\end{tabular} & $\begin{array}{c}\text { Classica } \\
1 \mathrm{ZSI} \\
\end{array}$ \\
\hline$v_{p h}$ & $\frac{2 M-M^{2}}{3 M-2} \frac{V_{d c}}{2}$ & $\frac{M}{3 M-2} \frac{V_{d c}}{2}$ & $\frac{2 M-M^{2}}{3 M-2} \frac{V_{d c}}{2}$ & $\frac{M}{2 M-1} \frac{V_{d c}}{2}$ & $\frac{M}{2 M-1} \frac{V_{d c}}{2}$ \\
\hline$V_{C}$ & $\frac{1}{M} \hat{v}_{p h}$ & $\frac{1}{M} \hat{v}_{p h}$ & $\frac{2}{2-M} \hat{v}_{p h}$ & $\frac{1}{M} \hat{v}_{p h}$ & $2 v_{p h}$ \\
\hline $\begin{array}{l}V_{P N} \\
V_{\text {Din }}\end{array}$ & $\frac{2}{M} \hat{v}_{p h}$ & $\frac{2}{M} \hat{v}_{p h}$ & $\frac{2}{M} \hat{v}_{p h}$ & $\frac{2}{M} \hat{v}_{p h}$ & $\frac{2}{M} \hat{v}_{p h}$ \\
\hline$I_{L}$ & $\frac{M^{2}}{3 M-2} \frac{V_{P N}}{R_{l}}$ & $\frac{M^{2}}{3 M-2} \frac{V_{P N}}{R_{l}}$ & $\frac{M^{2}}{3 M-2} \frac{V_{P N}}{R_{l}}$ & $\frac{M^{2}}{2 M-1} \frac{V_{P N}}{R_{l}}$ & $\frac{M^{2}}{2 M-1} \frac{V_{P N}}{R_{l}}$ \\
\hline$I_{\text {Din }}$ & $2 I_{L}-I_{l}$ & $2 I_{L}-I_{l}$ & $2 I_{L}-I_{l}$ & $2 I_{L}-I_{l}$ & $2 I_{L}-I_{l}$ \\
\hline$I_{s h}$ & $4 I_{L}$ & $4 I_{L}$ & $4 I_{L}$ & $2 I_{L}$ & $2 I_{L}$ \\
\hline$I_{l}$ & $M V_{P N} / R_{l}$ & $M V_{P N} / R_{l}$ & $M V_{P N} / R_{l}$ & $M V_{P N} / R_{l}$ & $M V_{P N} / R_{l}$ \\
\hline$i_{\text {in }}$ & $I_{L} ; 2 I_{L}$ & $\overline{I_{L}}$ & $\begin{array}{c}0 ; 2 I_{L}- \\
I_{l} ; 2 I_{L}\end{array}$ & $\overline{I_{L}}$ & $\begin{array}{c}0 ; 2 I_{L}-I_{l} \\
2 I_{L}\end{array}$ \\
\hline$\overline{I_{\text {in }}}$ & $(2-M) I_{L}$ & $I_{L}$ & $(2-M) I_{L}$ & $I_{L}$ & $I_{L}$ \\
\hline$\overline{\Delta I_{\text {in }}}$ & $\left|(1-M) I_{L}\right|$ & 0 & $\left|M \cdot I_{L}-I_{l}\right|$ & 0 & $\left|I_{L}-I_{l}\right|$ \\
\hline
\end{tabular}
$M$ AND $V_{D C}$

where $I_{\text {Din }}, I_{s h}, I_{l}, i_{\text {in }}$ and $R_{l}$ are the peak current across the diode $D_{\text {in }}$, the peak shoot-through current across the main power circuit during the shoot-through state, the average load current, the instantaneous input current, and the equivalent load register, respectively.

TABLE II

Governing CurRent and Voltage Equations for the SAme $V_{D C}, \hat{v}_{p h}$ AND $R_{L}$

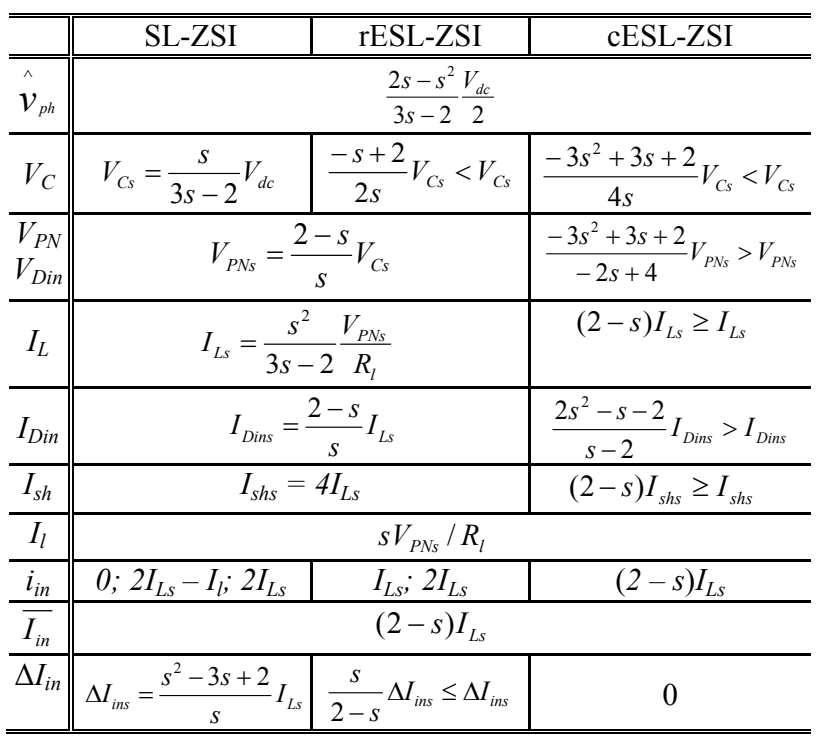

\section{SimUlation RESUltS}

PSIM simulations were used to verify the features of the proposed inverters as shown in Fig. 3. The simulation parameters were $L_{1}=L_{2}=L_{3}=L_{4}=1 \mathrm{mH}, C_{1}=C_{2}=1000 \mu \mathrm{F}$, and $V_{d c}=60 \mathrm{~V}$. The switching frequency was $10 \mathrm{kHz}$; the three-phase balanced load was $R=50 \Omega$ /phase and $L_{l}=4.5$ $\mathrm{mH} /$ phase. The simple boost control method was used. In the 


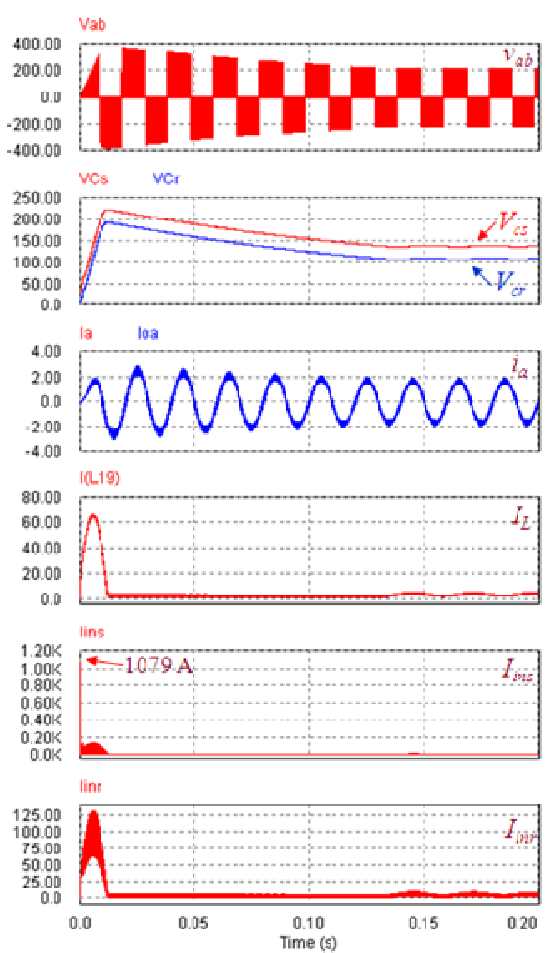

Fig. 12. Simulation results using simple boost control for rESL-ZSI and SL-ZSI with $M=0.78$ and $T_{0} / T=0.22$. From top to bottom: output line-to-line voltage $v_{a b}$, SL-ZSI capacitor voltage $V_{C s}$, rESL-ZSI capacitor voltage $V_{C r}$, output current $i_{a}$, inductor current $I_{L}$, SL-ZSI input current $I_{\text {ins }}$, and rESL-ZSI input current $I_{\text {inr }}$.
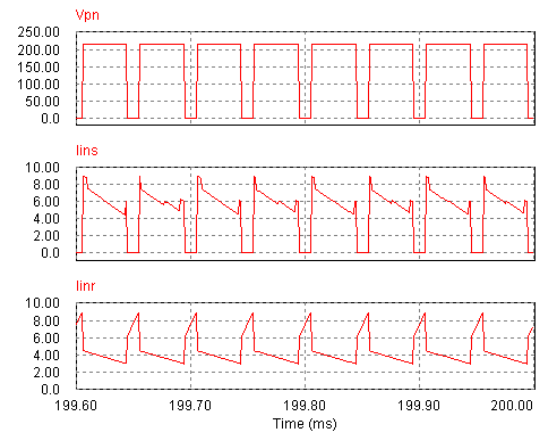

Fig. 13. Simulation results for enlarged steady state waveforms for rESL-ZSI and SL-ZSI with $M=0.78$ and $T_{0} / T=0.22$. Top: dc-link voltage, center: SL-ZSI input current, bottom: proposed rESL-ZSI input current.

simulation, all of the components were ideal; the initial state of the capacitors was set to $0 \mathrm{~V}$. For the proposed rESL-ZSI and the SL-ZSI, we set $M=0.78$. To produce the same output voltage as the proposed rESL-ZSI from the same input voltage, the modulation index for the proposed cESL-ZSI needed to be 0.757 .

Figs. 12 and 13 show the simulation results for the proposed rESL-ZSI and the SL-ZSI when $V_{d c l}=V_{d c 2}=30 \mathrm{~V}$, $M=0.78$ and $T_{0} / T=0.22$. From Figs. 12 and 13 , we can see that both the SL-ZSI and the rESL-ZSI produce the same 215

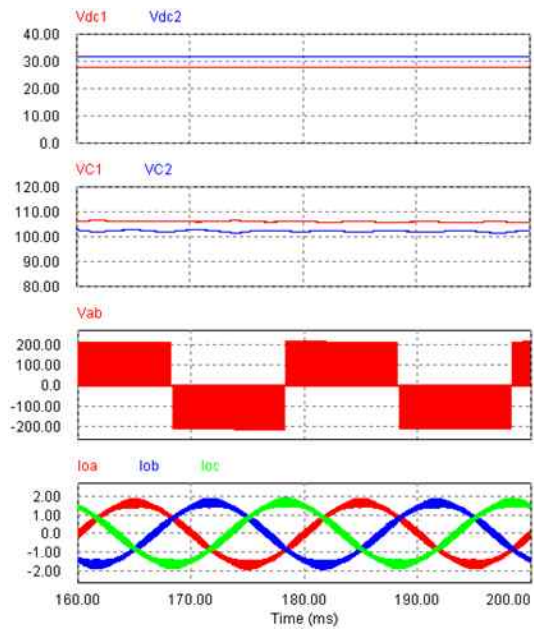

Fig. 14. Simulation results of the proposed rESL-ZSI when $V_{d c l}$ $=28 \mathrm{~V}, V_{d c 2}=32 \mathrm{~V}, M=0.78$ and $T_{0} / T=0.22$. From top to bottom: input voltages, capacitor voltages, line-to-line voltage and output phase currents.

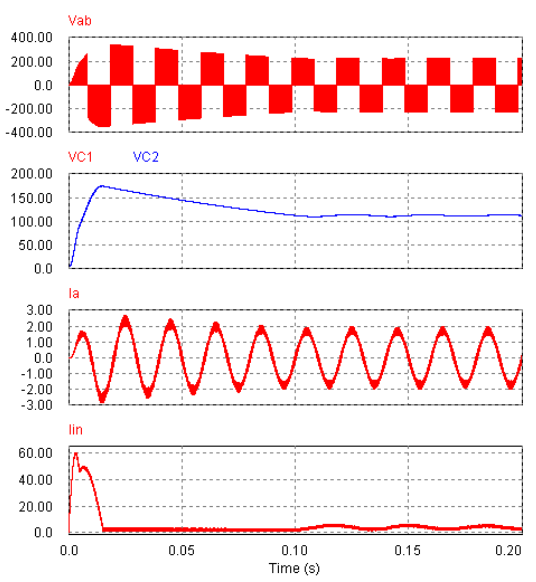

Fig. 15. Simulation results using simple boost control for cESL-ZSI with $M=0.757$ and $T_{0} / T=0.243$. From top to bottom: output line-to-line voltage, capacitor voltage, output current, and input current $I_{i n}$.

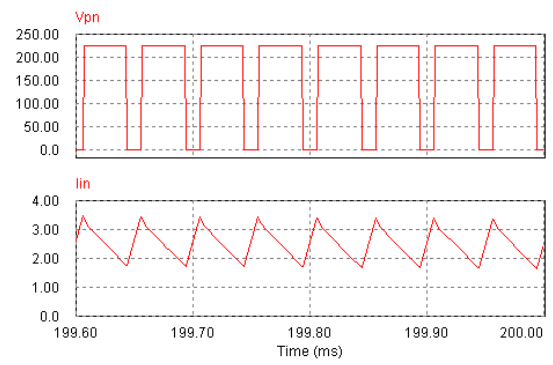

Fig. 16. Simulation results for enlarged cESL-ZSI waveforms in steady state with $M=0.757$ and $T_{0} / T=0.243$. Top: dc-link voltage, bottom: input current.

$\mathrm{V}$ peak dc-link voltage, $V_{P N}$ and the same $1.16 \mathrm{~A}_{\mathrm{rms}}$ phase current, $i_{a}$; the capacitor voltage for the SL-ZSI was boosted to $136 \mathrm{~V}$ whereas the capacitor voltage for the rESL-ZSI was $106 \mathrm{~V}$ in the steady state. The input current of the rESL-ZSI had a lower ripple than that found for the SL-ZSI. A huge 


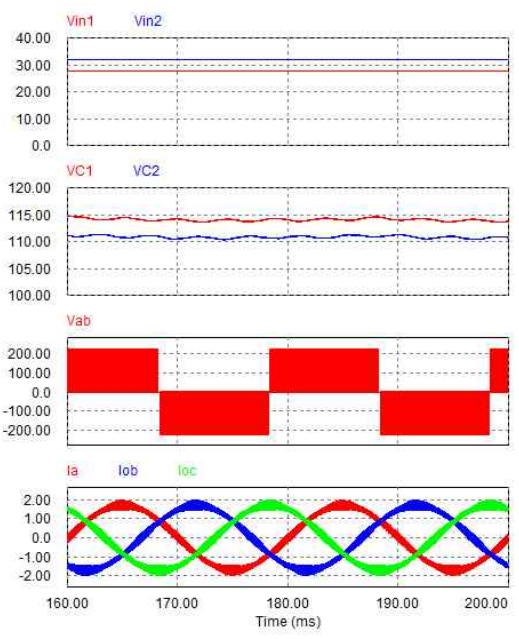

Fig. 17. Simulation results of the proposed cESL-ZSI when $V_{d c I}$ $=28 \mathrm{~V}, V_{d c 2}=32 \mathrm{~V}, M=0.757$ and $T_{0} / T=0.243$. From top to bottom: input voltages, capacitor voltages, line-to-line voltage and output phase currents.

inrush current that could destroy the devices occurred at the SL-ZSI startup.

In order to verify that there is no problem at the operation in case two split DC voltage sources $V_{d c} / 2$ are not identical, Fig. 14 shows the simulation results of the proposed rESL-ZSI when $V_{d c l}=28 \mathrm{~V}, V_{d c 2}=32 \mathrm{~V}, M=0.78$ and $T_{0} / T=$ 0.22 . The voltages of the capacitors $\left(C_{I}\right.$ and $\left.C_{2}\right)$ are respectively boosted to $109 \mathrm{~V}$ and $105 \mathrm{~V}$ from the total input voltage of $60 \mathrm{~V}$; the voltage gain is the same as in case $V_{d c l}=$ $V_{d c 2}=30 \mathrm{~V}$.

Figs. 15 and 16 show the simulation results for the proposed cESL-ZSI when $V_{d c 1}=V_{d c 2}=30 \mathrm{~V}, M=0.757$ and $T_{0} / T=0.243$. The peak dc-link voltage of the cESL-ZSI was boosted to $220 \mathrm{~V}$. The output phase current was also 1.16 Arms, and the capacitor voltage of the cESL-ZSI was boosted to $110 \mathrm{~V}$ in the steady state. The input current of the cESL-ZSI was flat and the same went for the inductor current. Fig. 17 shows the simulation results of the proposed rESL-ZSI when $V_{d c l}=28 \mathrm{~V}, V_{d c 2}=32 \mathrm{~V}, M=0.757$ and $T_{0} / T$ $=0.243$. The capacitor $C_{1}$ and $C_{2}$ voltages are respectively boosted to $112 \mathrm{~V}$ and $109 \mathrm{~V}$ from the total input voltage of 60 $\mathrm{V}$; the voltage gain is the same that in case $V_{d c 1}=V_{d c 2}=30 \mathrm{~V}$.

As shown in Figs. 12 to 17 , producing the same $1.16 \mathrm{~A}_{\text {rms }}$ output phase current from the $60 \mathrm{~V}$ input dc voltage creates a lower capacitor voltage stress, a lower input current ripple, and a smaller startup inrush current occurred in the proposed inverters, compared to the SL-ZSI. As shown in Fig. 12, the $V_{c s}$ of the capacitors in the SL-ZSI was initially at $30 \mathrm{~V}$, but had no initial value in the proposed rESL-ZSI and cESL-ZSI, as the initial voltage across the Z-source capacitors is zero and the huge inrush current flows through diode $D_{i n}, C_{1}, C_{2}$ and charges the capacitors immediately to $V_{c}=V_{d c} / 2=30 \mathrm{~V}$, as shown in Fig. 2 in the switched inductor Z-source inverter.

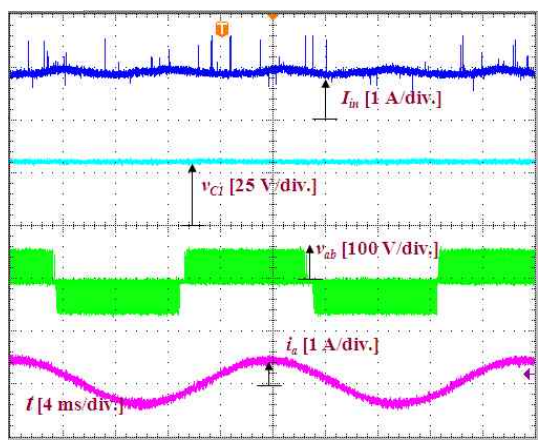

Fig. 18. Experiment waveforms of proposed rESL-ZSI when $M=$ 0.78 and $T_{0} / T=0.0$. From top to bottom: input current, capacitor $C_{l}$ voltage, output line-to-line voltage, and output phase current at $4 \mathrm{~ms} / \mathrm{div}$.

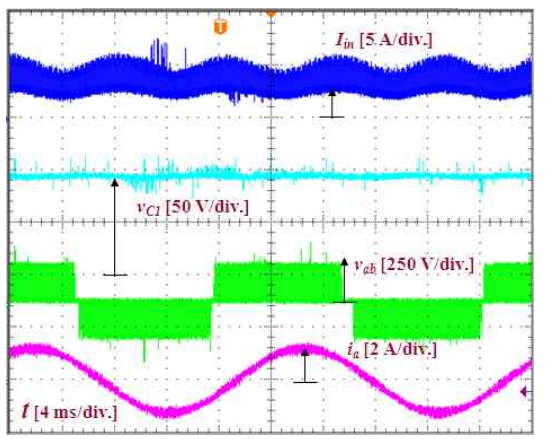

(a)

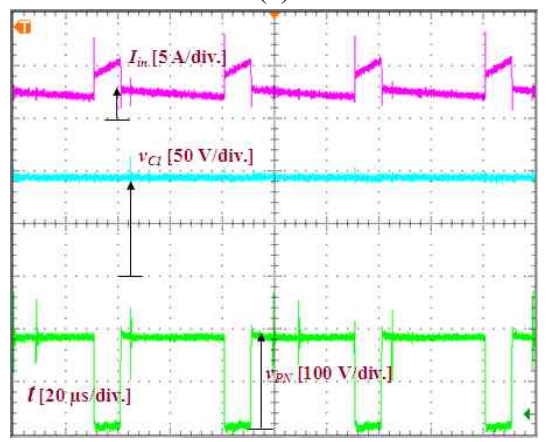

(b)

Fig. 19. Experiment results of proposed rESL-ZSI when $M=$ 0.78 and $T_{0} / T=0.22$. (a) From top to bottom: input current, capacitor $C_{I}$ voltage, output line-to-line voltage, and output phase current at $4 \mathrm{~ms} /$ div. (b) Top: input current, center: capacitor $C_{l}$ voltage, bottom: dc-link voltage at $20 \mu \mathrm{s} / \mathrm{div}$.

The capacitors in the proposed rESL-ZSI and cESL-ZSI have no initial value because no current flows to the main circuit at startup. In case two split DC voltage sources $V_{d c} / 2$ are not identical, Figs. 14 and 17 show that there is no problem at the operation of proposed topologies. In this case, the proposed inverter topologies are asymmetrical and thereby $V_{c 1} \neq V_{c 2}$.

\section{EXPERIMENTAL VERIFICATIONS}

We constructed a laboratory prototype based on a TMS320F2812 DSP in order to verify the properties of the proposed rESL-ZSI and cESL-ZSI. The prototype used the same parameters as used in the simulation. Fig. 18 shows the 


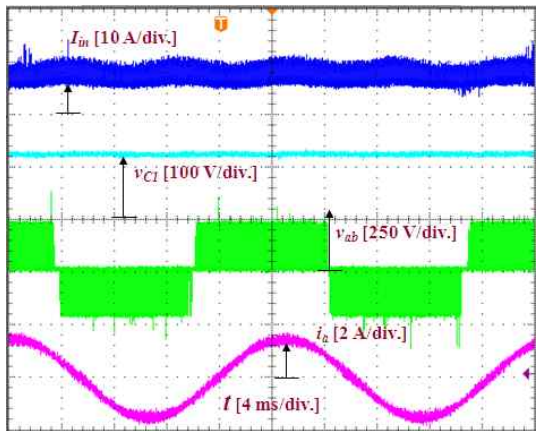

(a)

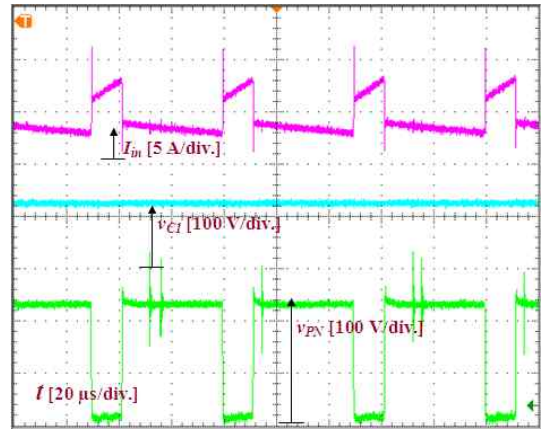

(b)

Fig. 20. Experiment results of proposed rESL-ZSI when $M=$ 0.76 and $T_{0} / T=0.24$. (a) From top to bottom: input current, capacitor $C_{l}$ voltage, output line-to-line voltage, and output phase current at $4 \mathrm{~ms} / \mathrm{div}$. (b) Top: input current, center: capacitor $C_{l}$ voltage, bottom: dc-link voltage at $20 \mu \mathrm{s} /$ div.

experimental results for the proposed rESL-ZSI without a shoot-through state when $M=0.78$ and $T_{0} / T=0.0$. In Fig. 18, the waveforms from top to bottom are the input current, capacitor $C_{I}$ voltage, output line-to-line voltage, and the output phase current. The peak line-to-line voltage pulse is equal to the $60 \mathrm{~V}$ of the dc input voltage. This matches the theoretical analysis for the non-shoot-through state case. Next, we tested the high boost ability of the proposed rESL-ZSI by keeping $M=0.78$ and increasing the shoot-through duration to $T_{0} / T=0.22$. Fig. 19 shows the experiment waveforms for the proposed rESL-ZSI when $M=0.78$ and $T_{0} / T=0.22$. The dc-link voltage was boosted from $60 \mathrm{~V}$ to $182 \mathrm{~V}$, the rms value of the phase current was $1 \mathrm{~A}_{\text {rms }}$, and the instantaneous input current was $I_{L}$ and $2 I_{L}$, sequentially.

In order to verify more clearly the performance of proposed rESL-ZSI, Fig. 20 shows the experimental results when $M=0.76$ and $T_{0} / T=0.24$. The dc-link voltage was boosted from $60 \mathrm{~V}$ to $220 \mathrm{~V}$, and the rms value of the phase current was $1.18 \mathrm{~A}$.

Next, the system was reconfigured to reflect the proposed cESL-ZSI topology. Fig. 21 shows the experimental results for the no shoot-through state when $M=0.757$ and $T_{0} / T=0.0$. The peak line-to-line voltage pulse was equal to the dc input voltage of $60 \mathrm{~V}$. We then set $T_{0} / T=0.243$ and kept $M=0.757$. Fig. 22 shows the experiment waveforms for the proposed rESL-ZSI when $M=0.757$ and $T_{0} / T=0.243$. The dc-link

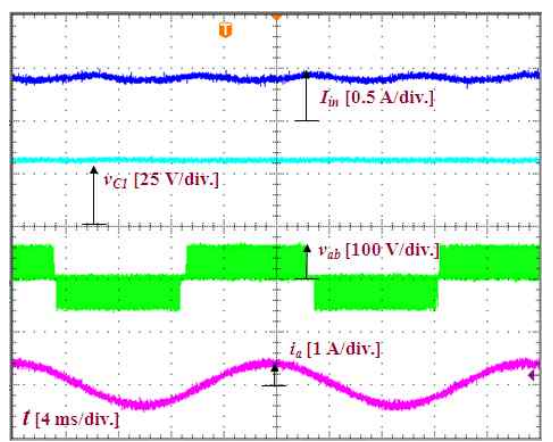

Fig. 21. Experiment waveforms of proposed cESL-ZSI when $M$ $=0.757$ and $T_{0} / T=0.0$. From top to bottom: input current, capacitor $C_{l}$ voltage, output line-to-line voltage, and output phase current at $4 \mathrm{~ms} / \mathrm{div}$.

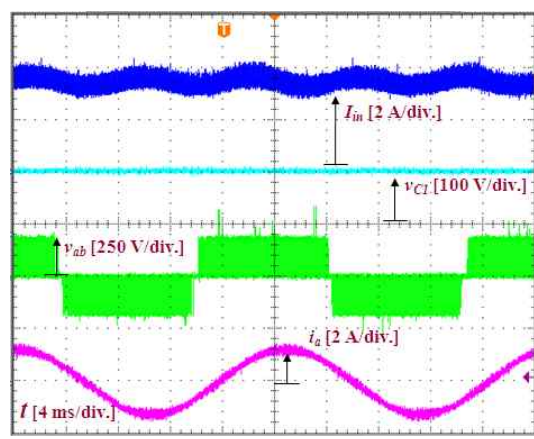

(a)

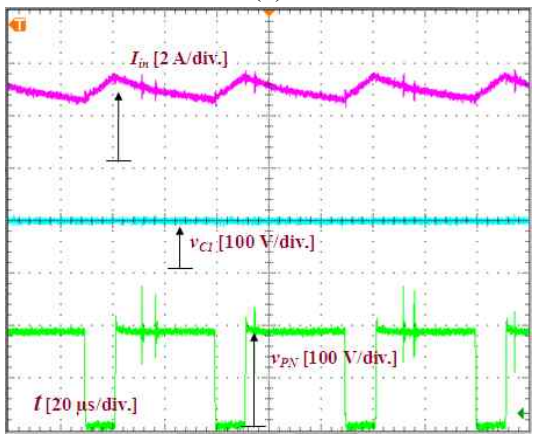

(b)

Fig. 22. Experiment results for proposed cESL-ZSI when $M=$ 0.757 and $T_{0} / T=0.243$. (a) From top to bottom: input current, capacitor $C_{I}$ voltage, output line-to-line voltage, and output phase current at $4 \mathrm{~ms} / \mathrm{div}$. (b) Top: input current, center: capacitor $C_{I}$ voltage, bottom: dc-link voltage at $20 \mu \mathrm{s} /$ div.

voltage was boosted from $60 \mathrm{~V}$ to $187 \mathrm{~V}$, the rms value of the phase current was $1 \mathrm{~A}_{\text {rms, }}$ and the input current was continuous.

For a higher voltage of the proposed cESL-ZSI, Fig. 23 shows the experimental results when $M=0.74$ and $T_{0} / T=$ 0.26 . The dc-link voltage was boosted from $60 \mathrm{~V}$ to $225 \mathrm{~V}$, the rms value of the phase current was $1.18 \mathrm{~A}_{\mathrm{rms}}$, and the input current was flatter than that shown in Figs. 19 and 20 of the rESL-ZSI.

From Figs. 19 and 22, we observe that the voltage gain in experiment results is lower than that in simulation results. This is due to the system parasites appeared in the 


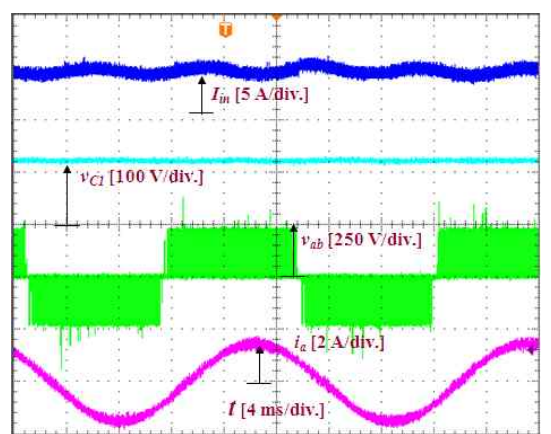

(a)

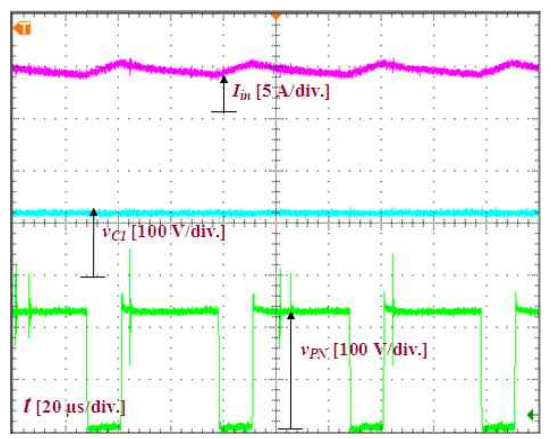

(b)

Fig. 23. Experiment results of proposed cESL-ZSI when $M=$ 0.74 and $T_{0} / T=0.26$. (a) From top to bottom: input current, capacitor $C_{1}$ voltage, output line-to-line voltage, and output phase current at $4 \mathrm{~ms} /$ div. (b) Top: input current, center: capacitor $C_{l}$ voltage, bottom: dc-link voltage at $20 \mu \mathrm{s} /$ div.

experimental setup. The measured efficiency of the proposed rESL-ZSI and cESL-ZSI at $1 \mathrm{~A}_{\text {rms }}$ output current approximates and only reaches $84.75 \%$. This may be because the circuit parameters have not been selected optimally. The semiconductors such as power switches and diodes are the main contributors to the total loss of the proposed inverters. The simulation and experimental results show that the proposed rESL-ZSI and cESL-ZSI achieve a high boost inversion compared to the classic ZSI. When compared to the SL-ZSI [14], the proposed rESL-ZSI and cESL-ZSI have a lower voltage stress on the capacitors and a lower input current ripple for the same input and output voltages. In addition, the proposed inverters eliminate the startup inrush current.

\section{CONCLUSIONS}

This paper proposed two types of embedded switched-inductor Z-source inverters, possessing either a ripple or continuous input current with the following main characteristics: a high boost voltage inversion ability and a continuous input current. Compared to the SL-ZSI, for the same input and output voltage, the proposed rESL-ZSI and cESL-ZSI offer reduced voltage stress on the capacitors, and can suppress the startup inrush current, which otherwise may destroy the devices. In addition, the dc input current in the proposed rESL-ZSI and cESL-ZSI flows smoothly without the need to add external second-order filters. Although the proposed rESL-ZSI can produce a higher output voltage gain in the case of the same modulation index and the same input voltage, its dc input current contains more ripple than that found in the proposed cESL-ZSI.

The experiment results for the $60 \mathrm{~V}_{\mathrm{dc}}$ input verified the high step-up inversion ability; the simulation and experimental results show that the proposed inverters have a high boost inversion ability. Compared with a traditional combination of dc-dc converter and inverter, the advantages of the proposed inverters are described as follows: 1) the upper and lower devices of the same phase leg in the proposed inverters can be gated on simultaneously and thereby eliminate the dead time, which significantly improves the reliability and reduces the output waveform distortion; 2) they offer a simplified single stage power conversion topology with one active switch less. The proposed rESL-ZSI and cESL-ZSI are applicable for fuel cells or photovoltaic applications where a low input voltage is inverted to a high ac output voltage.

\section{ACKNOWLEDGMENT}

This research is funded by Vietnam National Foundation for Science and Technology Development (NAFOSTED) under grant number 103.99-2012.22.

\section{REFERENCES}

[1] T. Kerekes, R. Teodorescu, M. Liserre, C. Klumpner, and M. Sumner, "Evaluation of three-phase transformerless photovoltaic inverter topologies," IEEE Trans. Power Electron., Vol. 24, No. 9, pp. 2202-2211, Sep. 2009.

[2] F. Z. Peng, "Z-source inverter," IEEE Trans. Ind. Appl., Vol. 39, No. 2, pp. 504-510, Mar./Apr. 2003.

[3] F. Z. Peng, M. Shen, and Z. Qian, "Maximum boost control of the Z-source inverter," IEEE Trans. Power Electron., Vol. 20, No. 4, pp. 833-838, Jul. 2005.

[4] M. Shen, J. Wang, A. Joseph, F. Z. Peng, L. M. Tolbert, and D. J. Adams, "Constant boost control of the Z-source inverter to minimize current ripple and voltage stress," IEEE Trans. Ind. Appl., Vol. 42, No. 3, pp. 770-778, May/Jun. 2006.

[5] M. G. H. Aghdam, "Z-Source inverter with sic power semiconductor devices for fuel cell vehicle applications," Journal of Power Electronics, Vol. 11, No. 4, pp. 606-611, Jul. 2011

[6] O. Ellabban, J. V. Mierlo, and P. Lataire, “ Control of a bidirectional z-source inverter for electric vehicle applications in different operation modes," Journal of Power Electronics, Vol. 11, No. 2, pp. 120-131, 2011

[7] J. B. Liu, J. G. Hu, and L. Y. Xu, "Dynamic modeling and analysis of Z-source converter-derivation of AC small signal model and design-oriented analysis," IEEE Trans. Power Electron., Vol. 22, No. 5, pp. 1786-1796, Sep. 2007.

[8] Q. V. Tran, T. W. Chun, H. G. Kim and E. C. Nho, "Minimization of voltage stress across switching devices in the Z-source inverter by capacitor voltage control," 
Journal of Power Electronics, Vol. 9, No. 3, pp. 335-342, May 2009.

[9] M. K. Nguyen, Y. G. Jung, and Y. C. Lim, "Single-phase ac-ac converter based on quasi-Z-source topology," IEEE Trans. Power Electron., Vol. 25, No. 8, pp. 2200 - 2210, Aug. 2010.

[10] M. K. Nguyen, Y. G. Jung, and Y. C. Lim, "Single-phase $\mathrm{Z}$-source ac/ac converter with wide range output voltage operation," Journal of Power Electronics, Vol. 9, No. 5, pp. 736-747, Sep. 2009.

[11] J. Anderson and F. Z. Peng, "Four quasi-Z-source inverters," in Proc. IEEE PESC'08, pp. 2743-2749, 2008.

[12] J. H. Park, H. G. Kim, E. C. Nho, and T. W. Chun, "Power conditioning system for a grid connected PV power generation using a quasi-Z-source inverter," Journal of Power Electronics, Vol. 10, No. 1, pp. 79-84, Jan. 2010.

[13] S. M. D. Dehnavi, M. Mohamadian, and A. Yazdian, "Current-type nine-switch inverters," Journal of Power Electronics, Vol. 10, No. 2, pp. 146-154, Mar. 2010.

[14] M. Zhu, K. Yu, and F. L. Luo, "Switched-inductor Z-source inverter," IEEE Trans. Power Electron., Vol. 25, No. 8, pp. 2150-2158, Aug. 2010.

[15] M. K. Nguyen, Y. C. Lim, and G. B. Cho, "Switched-inductor quasi-Z-source inverter," IEEE Trans. Power Electron., Vol. 26, No. 11, pp. 3183-3191, Nov. 2011.

[16] C. J. Gajanayake, F. L. Luo, H. B. Gooi, P. L. So, and L. $\mathrm{K}$. Siow, "Extended boost Z-source inverters," IEEE Trans. Power Electron., Vol. 25, No. 10, pp. 2642 - 2652, Oct. 2010.

[17] W. Qian, F. Z. Peng, and H. Cha, "Trans-Z-source inverters," in Proc. IEEE IPEC-Sapporo2010, pp. 1874-1881, 2010.

[18] B. Axelrod, Y. Berkovich, and A. Ioinovici, "Switched-capacitor/switched-inductor structures for getting transformerless hybrid dc-dc PWM converters," IEEE Trans. Circuits Syst. I, Fundam. Theory Appl., Vol. 55, No. 2, pp. 687-696, Mar. 2008.

[19] P. C. Loh, F. Gao, and F. Blaabjerg, "Embedded EZ-source inverters", IEEE Trans. Ind. Appl., Vol. 46, No. 1, pp. 256-267, Jan./Feb. 2010.

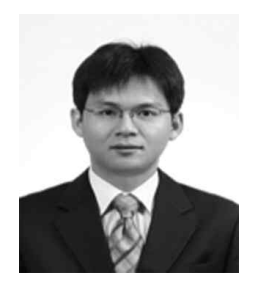

Minh-Khai Nguyen was born in Vietnam, in 1982. He received the B.S. degree in electrical and electronics engineering from Ho Chi Minh city University of Technology, Ho Chi Minh city, Vietnam, in 2005, and the M.S. and Ph.D. degrees in electrical engineering from Chonnam National University, Korea, in 2007 and 2010, respectively. Since 2010, he has been a lecturer with Nguyen Tat Thanh University, Ho Chi Minh city, Vietnam. In 2011 - 2012, he was a Visiting Researcher with the Robot Research Initiative Center, Chonnam National University, Korea. His current research interests include switched reluctance motor drives, power quality and Z-source converters.

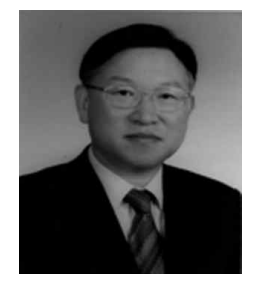

Young-Cheol Lim was born in Chonnam, Korea, in 1953. He received the B.S. degree in electrical engineering from Chonnam National University, Gwang-ju, Korea, in 1975, and the M.S. and Ph.D. degrees from the Korea University, Seoul, Korea, in 1977 and 1990, respectively. Since 1981, he has been a Professor with Chonnam National University, where he was the Director of the Research Center for High-Quality Electric Components and Systems from 1998 to 2007. He is the coauthor of three books. He has authored or coauthored more than 200 published technical papers. His current research interests include power electronics, control instruments, and neurofuzzy control. Prof. Lim was the President of Korea Institute of Power Electronics (KIPE) in 2009. He has been engaged with various academic societies, such as the KIPE, the Korean Institute of Electrical Engineers, and the Institute of Control, Automation, and Systems Engineers, Korea. He received a number of awards, including 2000 KIPE Best Paper Award, and 2001 KIPE Academic Award.

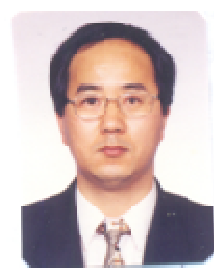

Young-Hak Chang was born in Chonnam, Korea in 1960. He received the B. S., M. S. and $\mathrm{Ph}$. D. degrees in electrical engineering from Chonnam National University, Gwangju, Korea, in 1981, 1984, and 1991, respectively. From 1997 to 1998 , he was a Visiting Professor at the Department of Electrical Engineering, Monash University, Australia. Since 1991, he is a Professor with the Department of Control and Robot Engineering, Mokpo National University, Mokpo, Korea. His current research interests include power electronics, motor drives and renewable energy.

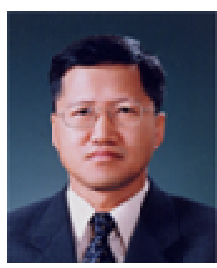

Chae-Joo Moon received the B.S., M.S. and $\mathrm{Ph} . \mathrm{D}$ degrees in Electrical Engineering from the Chonnam National University, Gwangju, Korea, in 1981, 1983 and 1994, respectively. He worked with Korea Power Engineering Co., Electric Power Research Team, from 1981 to 1997 . Since 1997, he has been with the Department of Electrical Engineering, Mokpo National University, where he is currently a professor and director for wind power test center. His research interests include battery management systems and small wind power control and converter systems. Dr. Moon is a member of the Korean Institute of Power Electronics (KIPE) and the Korean Institute of Electrical Engineers (KIEE). 